\title{
Decomposition of Generalized Closed Sets in Supra Topological Spaces
}

\author{
S. Dayana Mary \\ Assistant Professor \\ Coimbatore Institute of \\ Technology, Coimbatore, \\ India.
}

\author{
N. Nagaveni \\ Assistant Professor \\ Coimbatore Institute of \\ Technology, Coimbatore \\ India
}

\begin{abstract}
In this paper, we introduce a new class of sets called supra generalized locally closed sets and new class of maps called supra generalized locally continuous functions. Furthermore, we obtain some of their properties.

KEYWORDS S-GLC sets, S-GLC* sets, SGLC** sets, S-GL- continuous, S-GL*- continuous, SGL**- continuous, S-GL- irresolute, S-GL*- irresolute and S-GL**- irresolute
\end{abstract}

\section{INTRODUCTION}

In 1921, Kuratowski and Sierpinski [8] considered the difference of two closed subsets of an n-dimensional Euclidean space. Implicit in their work is the notion of a locally closed subset of a topological space. Bourbaki [2] defined a subset of space $(X, \tau)$ is called locally closed, if it is the intersection of an open set and a closed set. Stone [11] has used the term FG for a locally closed subset. Ganster and Reilly [4] and [5], Balachandran et al. [1] and J. H. Park et al. [6] introduced the concept of LCcontinuous functions, GLC continuous functions and SGLC*-continuous functions respectively.

Mashhour et al. [9] introduced the supra topological spaces and studied S-continuous functions and $\mathrm{S} *$-continuous functions. In 2008, Devi et al. [3] introduced and studied a class of sets and maps between topological spaces called supra $\alpha$-open sets and supra $\alpha$-continuous maps, respectively. In 2010, O.R. Sayed et al.[12], introduced and studied a class of sets and a class of maps between topological spaces called supra $b-$ open sets and supra $b-$ continuous maps, respectively. Supra g-closed sets, supra g-continous function and supra g-closed maps are introduced and investigated by Ravi et al. [10].

In this paper we introduce the concept of supra generalized locally closed sets and study its basic properties. Also we introduce the concepts of supra generalized locally continuous functions and investigate some of the basic properties for this class of functions.

\section{PRELIMINARIES}

Throughout this paper, $(\mathrm{X}, \tau),(\mathrm{Y}, \sigma)$ and $(\mathrm{Z}, \eta)$ (or simply, $\mathrm{X}, \mathrm{Y}$ and $\mathrm{Z}$ ) represent topological space on which no separation axioms are assumed, unless explicitly stated. For a subset $\mathrm{A}$ if $(\mathrm{X}, \tau), \mathrm{cl}(\mathrm{A})$ and int $(\mathrm{A})$ represent the closure of A with respect to $\tau$ and the interior of A with respect to $\tau$, respectively. Let $\mathrm{P}(\mathrm{X})$ be the power set of $\mathrm{X}$. The complement of $\mathrm{A}$ is denoted by $\mathrm{X}-\mathrm{A}$ or $\mathrm{A}^{\mathrm{c}}$.

Now we recall some definitions and results which are useful in the sequel.
2.1 Definition $[9,12]$ Let $X$ be a non-empty set. The subfamily $\mu \subseteq \mathrm{P}(\mathrm{X})$ is said to a supra topology on $\mathrm{X}$ if $X \in \mu$ and $\mu$ is closed under arbitrary unions. The pair $(\mathrm{X}, \mu)$ is called a supra topological space.

The elements of $\mu$ are said to be supra open in $(\mathrm{X}, \mu)$. Complement of supra open sets are called supra closed sets.

2.2 Definition [12] Let $A$ be a subset $(X, \mu)$. Then

(i) The supra closure of a set $\mathrm{A}$ is, denoted by $c l^{\mu}(A)$, defined as $c l^{\mu}(A)=\cap\{\mathrm{B}: \mathrm{B}$ is a supra closed and $\mathrm{A} \subseteq \mathrm{B}\}$.

(ii) The supra interior of a set $\mathrm{A}$ is, denoted by int $^{\mu}(A)$, defined as $\operatorname{int}^{\mu}(A)=\cup\{\mathrm{B}: \mathrm{B}$ is a supra open and $\mathrm{B} \subseteq \mathrm{A}\}$.

2.3 Definition [9] A Let $(X, \tau)$ be a topological space and $\mu$ be a supra topology of X. We call $\mu$ is a supra topology associated with $\tau$ if $\tau \subseteq \mu$.

2.4 Definition [3] Let $(X, \tau)$ and $(Y, \sigma)$ be two topological spaces and $\tau \subseteq \mu$. A function $\mathrm{f:}(\mathrm{X}, \tau) \rightarrow$ $(Y, \sigma)$ is called supra continuous, if the inverse image of each open set of $\mathrm{Y}$ is a supra open set in $\mathrm{X}$.

2.5 Definition [7] Let $(\mathrm{X}, \tau)$ and $(\mathrm{Y}, \sigma)$ be two topological spaces and $\mu$ and $\lambda$ be supra topologies associated with $\tau$ and $\sigma$ respectively. A function $\mathrm{f}$ : (X, $\tau$ ) $\rightarrow(Y, \sigma)$ is said to be supra irresolute , if $f^{-1}(A)$ is supra open set of $\mathrm{X}$ for every supra open set $\mathrm{A}$ in $\mathrm{Y}$.

2.6 Definition [10] Let $(X, \mu)$ be a supra topological space. A subset A of $\mathrm{X}$ is called supra g-closed if $c l^{\mu}(A) \subseteq \mathrm{U}$ whenever $\mathrm{A} \subseteq \mathrm{U}$ and $\mathrm{U}$ is supra open in $(\mathrm{X}, \mu)$.

2.7 Definition [10] A subset $A$ of $(X, \mu)$ is called supra g-open, if $\mathrm{A}^{\mathrm{c}}$ is supra g-closed.

2.8 Remark [10] Every supra closed set implies supra g-closed set, supra g-closed set need not imply supra closed sets, supra open set implies supra gopen and supra g-open need not imply supra open set.

2.9 Definition [10] Let $A$ be a subset $(X, \mu)$. Then

(i) The supra g- closure of a set $\mathrm{A}$ is, denoted by $c l_{g}^{\mu}(A)$, defined as $c l_{g}^{\mu}(A)=\cap\{\mathrm{B}: \mathrm{B}$ is a supra $\mathrm{g}$ closed and $\mathrm{A} \subseteq \mathrm{B}\}$.

(ii) The supra g-interior of a set $\mathrm{A}$ is, denoted by int $t_{g}^{\mu}(A)$, defined as $\operatorname{int}_{g}^{\mu}(A)=\cup\{\mathrm{B}: \mathrm{B}$ is a supra g-open and $\mathrm{B} \subseteq \mathrm{A}\}$. 
2.10 Remark [10] (i) Intersection of two supra g-closed sets is generally not a supra g-closed set.

(ii) Union of two supra g-open sets is generally not a supra g-open set.

2.11 Theorem [10] For the subsets A, B of a supra topological space $(X, \mu)$, the following statements hold.

(i) If A is supra g-closed, then $\mathrm{A}=c l_{g}^{\mu}(A)$

(ii) $\mathrm{A} \subseteq c l_{g}^{\mu}(A) \subseteq c l_{g}^{\mu}(A)$

(iii) If $\mathrm{A} \subseteq \mathrm{B}$, then $c l_{g}^{\mu}(A) \subseteq c l_{g}^{\mu}(B)$

(iv) $c l_{g}^{\mu}(A)$ is supra g-closed.

\section{SUPRA GENERALIZED LOCALLY CLOSED SETS}

In this section, we introduce the notions of supra generalized locally closed sets and discuss some of their properties.

3.1 Definition Let $(X, \mu)$ be a supra topological space. A subset $\mathrm{A}$ of $(X, \mu)$ is called supra generalized locally closed set (briefly supra g-locally closed set), if $\mathrm{A}=\mathrm{U} \cap \mathrm{V}$, where $\mathrm{U}$ is supra g-open in $(\mathrm{X}, \mu)$ and $\mathrm{V}$ is supra g-closed in $(X, \mu)$.

The collection of all supra generalized locally closed sets of X will be denoted by S-GLC(X).

3.2 Remark Every supra g-closed set (resp. supra g-open set) is S-GLC.

3.3 Definition For a subset A of supra topological space $(X, \mu), A \in S_{-}-G L C^{*}(X, \mu)$, if there exist a supra $g$ open set $\mathrm{U}$ and a supra closed set $\mathrm{V}$ of $(\mathrm{X}, \mu)$, respectively such that $\mathrm{A}=\mathrm{U} \cap \mathrm{V}$.

3.4 Definition For a subset $A$ of $(X, \mu), A \in S$ $\operatorname{GLC}^{* *}(\mathrm{X}, \mu)$, if there exist an supra open set $\mathrm{U}$ and a supra g-closed set $\mathrm{V}$ of $(\mathrm{X}, \mu)$, respectively such that $\mathrm{A}=\mathrm{U}$ $\cap \mathrm{V}$.

3.5 Theorem Let $\mathrm{A}$ be a subset of $(\mathrm{X}, \mu)$. If $\mathrm{A} \in \mathrm{S}$ $\mathrm{GLC}^{*}(\mathrm{X}, \mu)$ or $\mathrm{A} \in \mathrm{S}-\mathrm{GLC}^{* *}(\mathrm{X}, \mu)$, then $\mathrm{A}$ is S-GLC.

Proof The proof is obvious from remark 1 of the preliminaries, definitions and the following example.

3.6 Example Let $X=\{a, b, c\}$ and $\mu=\{\phi, X,\{a$, b\}, $\{a, c\}\}$ b $\},\{a, c\}\}$

Then $\operatorname{S-GLC}^{*}(X, \mu)=\{\phi, X,\{a\},\{b\},\{c\},\{a$ $\{a, c\}\}$.

S-GLC**(X, $\mu)=\{\phi, X,\{b\},\{c\},\{a, b\},\{b, c\}$,

From this, S-GLC* $(X, \mu)$ and S-GLC**(X, $\mu)$ are the proper subset of S-GLC $(X, \mu)$, because S-GLC $(X$, $\mu)=P(X)$.

3.7 Theorem For a subset A of $(X, \mu)$, the following are equivalent:
(i) $\quad \mathrm{A} \in \mathrm{S}-\mathrm{GLC} *(\mathrm{X}, \mu)$
(ii) $\quad \mathrm{A}=\mathrm{U} \cap c l^{\mu}(A)$, for some supra $\mathrm{g}$ - open set $\mathrm{U}$.
(iii) $\quad c l^{\mu}(A)-\mathrm{A}$ is supra g-closed.
(iv) $\quad \mathrm{A} \cup\left[\mathrm{X}-\mathrm{Cl}^{\mu}(A)\right]$ is supra g-open.

Proof (i) $\Rightarrow$ (ii):Given A $\in$ S-GLC* $(X, \mu)$

Then there exist a supra $\mathrm{g}$-open subset $\mathrm{U}$ and a supra closed subset $\mathrm{V}$ such that $\mathrm{A}=\mathrm{U} \cap \mathrm{V}$. Since $\mathrm{A} \subset \mathrm{U}$ and $\mathrm{A}$ $\subset c l^{\mu}(A), \mathrm{A} \subset \mathrm{U} \cap c l^{\mu}(A)$.

Conversely, $c l^{\mu}(A) \subset \mathrm{V}$ and hence $\mathrm{A}=\mathrm{U} \cap \mathrm{V} \supset$ $\mathrm{U} \cap\left(c l^{\mu}(A)\right)$. Therefore, $\mathrm{A}=\mathrm{U} \cap c l^{\mu}(A)$
(ii) $\Rightarrow$ (i):
Let $\mathrm{A}=\mathrm{U} \cap c l^{\mu}(A)$, for

some supra g-open set $\mathrm{U}$. Then, $c l^{\mu}(A)$ is supra closed and hence $\mathrm{A}=\mathrm{U} \cap c l^{\mu}(A) \in \mathrm{S}-\mathrm{GLC}^{*}(\mathrm{X}, \mu)$.

$$
\text { (ii) } \Rightarrow \text { (iii): } \quad \text { Let } \mathrm{A}=\mathrm{U} \cap c l^{\mu}(A) \text {, for }
$$

some supra g-open set $\mathrm{U}$.

Then $\mathrm{A} \in \mathrm{S}$-GLC $*(\mathrm{X}, \mu)$. This implies $\mathrm{U}$ is supra g-open and $c l^{\mu}(A)$ is supra closed. Therefore, $c l^{\mu}(A)-\mathrm{A}$ is supra g-closed.

$$
\text { (iii) } \Rightarrow \text { (ii): } \quad \text { Let } \mathrm{U}=\mathrm{X}-\left[c l^{\mu}(A)-\mathrm{A}\right] .
$$

By (iii), $\mathrm{U}$ is supra g-open in $\mathrm{X}$. Then $\mathrm{A}=\mathrm{U} \cap$ $c l^{\mu}(A)$ holds.

$$
\text { (iii) } \Rightarrow \text { (iv): } \quad \text { Let } \quad \mathrm{Q}=c l^{\mu}(A)-\mathrm{A} \text { be }
$$

supra g-closed. Then $\mathrm{X}-\mathrm{Q}=\mathrm{X}-\left[{ }_{[} l^{\mu}(A)-\mathrm{A}\right]=\mathrm{A} \cup$ $\left[\left(\mathrm{X}-c l^{\mu}(A)\right]\right.$. Since $\mathrm{X}-\mathrm{Q}$ is supra g-open, $\mathrm{A} \cup[\mathrm{X}$ $\left.c l^{\mu}(A)\right]$ is supra g-open.

(vi) $\Rightarrow$ (iii): $\quad$ Let $\quad \mathrm{U}=\mathrm{A} \cup[$ (X$c l^{\mu}(A)$ ]. Since $\mathrm{X}-\mathrm{U}$ is supra g-closed and $\mathrm{X}-\mathrm{U}=$ $c l^{\mu}(A)$ - A is supra g-closed.

3.8 Theorem For a subset A of $(X, \mu)$, the following are equivalent:
(i)
$\mathrm{A} \in \mathrm{S}-\mathrm{GLC}(\mathrm{X}, \mu)$.
(ii)
$\mathrm{A}=\mathrm{U} \cap c l_{g}^{\mu}(A)$, for some supra $\mathrm{g}$ - open set $\mathrm{S}$.
(iii)
$c l_{g}^{\mu}(A)$ - A is supra g-closed.
(iv) $\quad \mathrm{A} \cup\left[\mathrm{X}-c l_{g}^{\mu}(A)\right]$ is supra g-open.

Proof (i) $\Rightarrow$ (ii): $\quad$ Given $A \in \mathrm{S}-\mathrm{GLC}(\mathrm{X}, \mu)$

Then there exist a supra g-open subset $U$ and a supra $g$ closed subset $\mathrm{V}$ such that $\mathrm{A}=\mathrm{U} \cap \mathrm{V}$. Since $\mathrm{A} \subset \mathrm{U}$ and $\mathrm{A}$ $\subset c l_{g}^{\mu}(A), \mathrm{A} \subset \mathrm{U} \cap c l_{g}^{\mu}(A)$.

Conversely by theorem 1(iv) of the preliminaries, of the preliminaries, $c l_{g}^{\mu}(A) \subset \mathrm{V}$ and hence $\mathrm{A}=\mathrm{U} \cap \mathrm{V} \supset$ $\mathrm{U} \cap c l_{g}^{\mu}(A)$. Therefore, $\mathrm{A}=\mathrm{U} \cap c l_{g}^{\mu}(A)$.

$$
\text { (ii) } \Rightarrow \text { (i): } \quad \text { Let } \mathrm{A}=\mathrm{U} \cap c l_{g}^{\mu}(A) \text {, for }
$$

some supra g-open set U. By theorem 1(iv) of the preliminaries, $C l_{g}^{\mu}(A)$ is supra g-closed and hence $\mathrm{A}=$ $\mathrm{U} \cap c l^{\mu}(A) \in \mathrm{S}^{-\mathrm{GLC}^{*}}(\mathrm{X}, \mu)$.

$$
\text { (ii) } \Rightarrow \text { (iii): } \quad \text { Let } \mathrm{A}=\mathrm{U} \cap c l_{g}^{\mu}(A) \text {, for }
$$

some supra g-open set $\mathrm{U}$. 
Then $\mathrm{A} \in \mathrm{S}$-GLC $(\mathrm{X}, \mu)$. This implies $\mathrm{U}$ is supra g-open and $c l_{g}^{\mu}(A)$ is supra g-closed. Therefore, $c l_{g}^{\mu}(A)-\mathrm{A}$ is supra g-closed.

$$
\text { (iii) } \Rightarrow \text { (ii): } \quad \text { Let } \mathrm{U}=\mathrm{X}-\left[c l_{g}^{\mu}(A)-\mathrm{A}\right] \text {. }
$$

By (iii), $\mathrm{U}$ is supra g-open in $\mathrm{X}$. Then $\mathrm{A}=\mathrm{U} \cap$ $c l_{g}^{\mu}(A)$ holds.

$$
\text { (iii) } \Rightarrow \text { (iv): } \quad \text { Let } \mathrm{Q}=c l_{g}^{\mu}(A)_{-\mathrm{A}} \text { be }
$$

supra g-closed. Then $\mathrm{X}-\mathrm{Q}=\mathrm{X}-\left[c l_{g}^{\mu}(A)-\mathrm{A}\right]=\mathrm{A} \cup$ $\left[\left(\mathrm{X}-c l_{g}^{\mu}(A)\right]\right.$. Since $\mathrm{X}-\mathrm{Q}$ is supra g-open, $\mathrm{A} \cup[\mathrm{X}$ $\left.c l_{g}^{\mu}(A)\right]$ is supra g-open.

(vi) $\Rightarrow$ (iii): $\quad$ Let $\quad U=A \cup[(X-$ $c l_{g}^{\mu}(A)$. Since $\mathrm{X}-\mathrm{U}$ is supra g-closed and $\mathrm{X}-\mathrm{U}=$ $c l_{g}^{\mu}(A)$ - A is supra g-closed.

3.9 Theorem For a subset $A$ of $(X, \mu)$, if $A \in S$ $\operatorname{GLC}^{* *}(\mathrm{X}, \mu)$, then there exist an supra open set $\mathrm{G}$ such that $\mathrm{A}=\mathrm{G} \cap \mathrm{C} l^{\mu}(A)$.

Proof Let $A \in S-G L C * *(X, \mu)$. Then $A=G \cap V$, where $G$ is supra open set and $V$ is supra g-closed set. Then $\mathrm{A}=\mathrm{G} \cap \mathrm{V} \Rightarrow \mathrm{A} \subset \mathrm{G}$.

Obviously, $\mathrm{A} \subset c l^{\mu}(A)$. Therefore, $\mathrm{A} \subset \mathrm{G} \cap$ $c l^{\mu}(A)$

$$
\begin{array}{r}
\text { Also we have } c l^{\mu}(A) \subset \mathrm{V} \text {. This implies } \mathrm{A}= \\
\mathrm{G} \cap \mathrm{V} \supset \mathrm{G} \cap c l^{\mu}(A) \Rightarrow \mathrm{A} \supset \mathrm{G} \cap c l^{\mu}(A) \text {----(2) } \\
\text { From (1) and (2), we get } \mathrm{A}=\mathrm{G} \cap c l^{\mu}(A) \text {. }
\end{array}
$$

3.10 Theorem For a subset $A$ of $(X, \mu)$, if $A \in S$ $\mathrm{GLC}^{* *}(\mathrm{X}, \mu)$, then there exist an supra open set $\mathrm{G}$ such that $\mathrm{A}=\mathrm{G} \cap C l_{g}^{\mu}(A)$.

\section{Proof Let $A \in S-G L C * *(X, \mu)$.}

Then $A=G \cap V$, where $G$ is supra open set and $V$ is supra g-closed set.

Then $\mathrm{A}=\mathrm{G} \cap \mathrm{V} \Rightarrow \mathrm{A} \subset \mathrm{G}$. By theorem 1(ii) in the preliminaries, $\mathrm{A} \subset c l_{g}^{\mu}(A)$. Therefore, $\mathrm{A} \subset \mathrm{G} \cap$ $c l_{g}^{\mu}(A)$

$$
\begin{array}{r}
\text { Also we have } c l_{g}^{\mu}(A) \subset \mathrm{V} \text {. This implies, } \mathrm{A}= \\
\mathrm{G} \cap \mathrm{V} \supset \mathrm{G} \cap C l_{g}^{\mu}(A) \Rightarrow \mathrm{A} \supset \mathrm{G} \cap C l_{g}^{\mu}(A) \text {---- ( } 2 \\
\text { From (1) and (2), we get } \mathrm{A}=\mathrm{G} \cap C l_{g}^{\mu}(A) .
\end{array}
$$

3.11 Theorem Let $A$ be a subset of $(X, \mu)$. If $A \in S$ GLC**(X, $\mu)$, then $c l_{g}^{\mu}(A)$ - A supra g-closed and A $\cup$ $\left[\left(\mathrm{X}-c l_{g}^{\mu}(A)\right]\right.$ is supra g-open.

Proof The proof is obvious from the definitions and results.

3.12 Remark The converse of the above theorem need not be true as seen the following example.
3.13 Example Let $X=\{a, b, c\}$ and $\mu=\{\phi, X,\{a$, $\mathrm{b}\},\{a, c\}\}$. Then $\{\phi, X,\{b\},\{c\},\{b, c\}\}$ is the set of all supra g-closed sets in $X$ and $\operatorname{SGLC}^{* *}(X, \mu)=P(X)-\{a\}$. If $\mathrm{A}=\{\mathrm{a}\}$, then $c l_{g}^{\mu}(A)-\mathrm{A}=\{\mathrm{b}, \mathrm{c}\}$ is supra g-closed and $\mathrm{A} \cup\left[\left(\mathrm{X}-c l_{g}^{\mu}(A)\right]=\mathrm{A}\right.$ is supra g-open but $\mathrm{A} \notin \mathrm{S}$ $\operatorname{GLC}^{* *}(\mathrm{X}, \mu)$.

3.14 Theorem Let $A \in S-G L C^{*}(X, \mu)$ and $B \in S$ $\mathrm{GLC}^{*}(\mathrm{X}, \mu)$. If $\mathrm{A}$ and $\mathrm{B}$ are supra separated, then $\mathrm{A} \cup \mathrm{B}$ $\notin$ S-GLC*(X, $\mu)$.

Proof Let $A \in \mathrm{S}-G L C^{*}(X, \mu)$ and $B \in \operatorname{S-GLC}^{*}(X, \mu)$. Suppose let us assume $A \cup B \in \operatorname{S-GLC} *(X, \mu)$. By theorem 2, there exist supra g-open sets $U$ and $V$ of $(X, \mu)$ such that $\mathrm{A}=\mathrm{U} \cap C l^{\mu}(A)$ and $\mathrm{B}=\mathrm{V} \cap C l^{\mu}(B)$. Put $\left.\mathrm{G}=\mathrm{U} \cap\left[\mathrm{X}-c l^{\mu}(B)\right)\right]$ and $\mathrm{H}=\mathrm{V} \cap[\mathrm{X}$ $\left.c l^{\mu}(A)\right]$. Then $\mathrm{A}=\mathrm{G} \cap c l^{\mu}(A)$ and $\mathrm{B}=\mathrm{H} \cap$ $c l^{\mu}(B)$. Also $\mathrm{G} \cap c l^{\mu}(B)=\phi$ and $\mathrm{H} \cap c l^{\mu}(A)$ $=\phi$. Hence it follows that $\mathrm{G}$ and $\mathrm{H}$ are supra g-open sets of $(\mathrm{X}, \mu)$. Therefore $\mathrm{A} \cup \mathrm{B}=\left[\mathrm{G} \cap \mathrm{C} l^{\mu}(A)\right] \cup[\mathrm{H} \cap$ $\left.c l^{\mu}(B)\right] \in \mathrm{S}-\mathrm{GLC} *(\mathrm{X}, \mu)$, by our assumption. Then $(\mathrm{G} \cup \mathrm{H}) \cap\left[C l^{\mu}(A) \cup c l^{\mu}(B)\right] \in \mathrm{S}-\operatorname{GLC}^{*}(\mathrm{X}, \mu)$. This implies $(\mathrm{G} \cup \mathrm{H}$ ) is supra g-open, but it is contradiction to the Remark 2(ii). Hence our assumption is wrong. Thus $\mathrm{A} \cup \mathrm{B} \notin \mathrm{S}-\mathrm{GLC}^{*}(\mathrm{X}, \mu)$.

3.15 Remark The following is one of the example of the above theorem.

3.16 Example Let $X=\{a, b, c\}$ and $\mu=\{\phi, X,\{b$, $c\},\{a, c\},\{a, b, c\},\{a, b, d\},\{b, c, d\}\}$. Let $A=\{a\}$ and $B$ $=\{b\}$. Then $\mathrm{A}$ and $\mathrm{B}$ are supra separated, because $\mathrm{A} \cap$ $c l^{\mu}(B)=\mathrm{B} \cap c l^{\mu}(A)=\phi$. Then $\mathrm{A} \cup \mathrm{B}=\{\mathrm{a}, \mathrm{b}\} \notin$

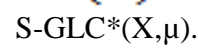

\section{SUPRA GENERALIZED LOCALLY CONTINUOUS FUNCTIONS}

In this section we define a new type of functions called Supra generalized locally continuous functions (S-GLcontinuous functions), supra generalized locally irresolute functions and study some of their properties.

4.1 Definition Let $(X, \tau)$ and $(Y, \sigma)$ be two topological spaces and $\tau \subseteq \mu$. A function $\mathrm{f}:(\mathrm{X}, \tau) \rightarrow$ $(\mathrm{Y}, \sigma)$ is called S-GL - continuous (resp., S-GL* continuous, resp., S-GL** - continuous), if $\mathrm{f}^{-1}(\mathrm{~A}) \in \mathrm{S}$ $\operatorname{GLC}(\mathrm{X}, \mu),\left(\right.$ resp., $\mathrm{f}^{-1}(\mathrm{~A}) \in \mathrm{S}-\mathrm{GLC}^{*}(\mathrm{X}, \mu)$, resp., $\mathrm{f}^{-1}(\mathrm{~A}) \in$ $\operatorname{S-GLC**}(X, \mu))$ for each $A \in \sigma$.

4.2 Definition Let $(X, \tau)$ and $(Y, \sigma)$ be two topological spaces and $\mu$ and $\lambda$ be a supra topologies associated with $\tau$ and $\sigma$ respectively. A function $\mathrm{f}$ : (X, $\tau) \rightarrow(\mathrm{Y}, \sigma)$ is said to be S-GL - irresolute (resp., S-GL* irresolute, resp., S-GL** - irresolute) if $\mathrm{f}^{1}(\mathrm{~A}) \in \mathrm{S}$-GLC $(\mathrm{X}, \mu),\left(\right.$ resp., $\mathrm{f}^{-1}(\mathrm{~A}) \in \mathrm{S}$-GLC* $(\mathrm{X}, \mu)$, resp., $\mathrm{f}^{-1}(\mathrm{~A}) \in \mathrm{S}$ $\left.\operatorname{GLC}^{* *}(\mathrm{X}, \mu)\right)$ for each $\mathrm{A} \in \mathrm{S}$-GLC $(\mathrm{Y}, \lambda)$ (resp., $\mathrm{A} \in \mathrm{S}$ $\operatorname{GLC}^{*}(\mathrm{Y}, \lambda)$, resp., $\left.\mathrm{A} \in \mathrm{S}-\mathrm{GLC}^{*}(\mathrm{Y}, \lambda)\right)$.

4.3 Theorem 4.3 Let $(X, \tau)$ and $(Y, \sigma)$ be two topological spaces and $\mu$ be a supra topology associated with $\tau$. Let $\mathrm{f:}(\mathrm{X}, \tau) \rightarrow(\mathrm{Y}, \sigma)$ be a function. If $\mathrm{f}$ is $\mathrm{S}-\mathrm{GL}^{*}-$ 
continuous or S-GL** - continuous, then it is S-GL continuous.

Proof The proof is trivial from the definitions.

4.4 Theorem Let $(\mathrm{X}, \tau)$ and $(\mathrm{Y}, \sigma)$ be two topological spaces and $\mu$ and $\lambda$ be a supra topologies associated with $\tau$ and $\sigma$ respectively. Let $\mathrm{f}:(\mathrm{x}, \mu) \rightarrow$ $(\mathrm{y}, \sigma)$ be a function. If $\mathrm{f}$ is $\mathrm{S}-\mathrm{GL}-$ irresolute (respectively $\mathrm{S}$ GL* - irresolute, respectively S-GL** - irresolute), then it is S-GL - continuous. (respectively S-GL* - continuous, respectively $\mathrm{S}-\mathrm{GL}^{* *}$ - continuous).

Proof By the definitions the proof is immediate.

4.5 Remark Converse of theorem 8 need not be true as seen from the following example.

4.6 Example Let $\mathrm{X}=\mathrm{Y}=\{\mathrm{a}, \mathrm{b}, \mathrm{c}\}$ with $\tau=\{\phi, \mathrm{X}$, $\{\mathrm{a}, \mathrm{b}\}\}, \sigma=\{\{\phi, \mathrm{Y},\{\mathrm{b}\}\}$ and $\mu=\{\phi, \mathrm{X},\{\mathrm{a}, \mathrm{b}\},\{\mathrm{b}, \mathrm{c}\}\}$. Let $\mathrm{f}:(\mathrm{X}, \mu) \rightarrow(\mathrm{Y}, \sigma)$ be the identity map. S-GLC $(\mathrm{X}, \mu)$ $=P(X), S-G L C *(X, \mu)=\{\phi, X,\{a\},\{b\},\{c\},\{a, b\},\{b$, c $\}\}$ and S-GLC** $(X, \mu)=\{\phi, X,\{a\},\{c\},\{a, b\},\{b, c\}$, $\{\mathrm{a}, \mathrm{c}\}\}$.

Here $\mathrm{f}$ is not $\mathrm{S}-\mathrm{GL}^{* *}$ - continuous, but it is $\mathrm{S}$ GL- continuous. Also $\mathrm{f}$ is not S-GL**-continuous, but it is and S-GL* - continuous.

4.7 Remark The following example provides a function which is $\mathrm{S}-\mathrm{GL}^{*}$ - continuous function but not $\mathrm{S}$ $-\mathrm{GL}^{*}$ - irresolute function.

4.8 Example Let $\mathrm{X}=\mathrm{Y}=\{\mathrm{a}, \mathrm{b}, \mathrm{c}\}$ with $\tau=\{\phi, \mathrm{X}$, $\{\mathrm{a}, \mathrm{b}\}\}, \sigma=\{\{\phi, \mathrm{Y},\{\mathrm{b}\}\}, \mu=\{\phi, \mathrm{X},\{\mathrm{a}, \mathrm{b}\},\{\mathrm{b}, \mathrm{c}\}\}$ and $\lambda$ $=\{\phi, X,\{b\},\{a, b\}\}$. Let $f:(X, \mu) \rightarrow(Y, \sigma)$ be the identity map. Here $\mathrm{f}$ is not $\mathrm{S}-\mathrm{GL}^{*}$ - irresolute, but it is $\mathrm{S}-\mathrm{GL}^{*}$ continuous.

4.9 Theorem If $\mathrm{g}: \mathrm{X} \rightarrow \mathrm{Y}$ is $\mathrm{S}-\mathrm{GL}$ - continuous and $: \mathrm{Y} \rightarrow \mathrm{Z}$ is supra continuous, then hog $: \mathrm{X} \rightarrow \mathrm{Z}$ is $\mathrm{S}-\mathrm{GL}-$ continuous.

Proof Let $\mathrm{g}: \mathrm{X} \rightarrow \mathrm{Y}$ is $\mathrm{S}-\mathrm{GL}-$ continuous and $\mathrm{h}: \mathrm{Y} \rightarrow$ $\mathrm{Z}$ is supra continuous. By the definitions, $\mathrm{g}^{-1}(\mathrm{~V}) \in \mathrm{S}$-GLC $(\mathrm{X}), \mathrm{V} \in \mathrm{Y}$ and

$\mathrm{h}^{-1}(\mathrm{~W}) \in \mathrm{Y}, \mathrm{W} \in \mathrm{Z}$. Let $\mathrm{W} \in \mathrm{Z}$. Then $(\mathrm{hog})^{-1}(\mathrm{~W})=\left(\mathrm{g}^{-1} \mathrm{~h}\right.$ $\left.{ }^{1}\right)(\mathrm{W})=$

$\mathrm{g}^{-1}\left(\mathrm{~h}^{-1}(\mathrm{~W})\right)=\mathrm{g}^{-1}(\mathrm{~V})$, for $\mathrm{V} \in \mathrm{Y}$. From this, $(h \circ)^{-1}(\mathrm{~W})=$ $\mathrm{g}^{-1}(\mathrm{~V}) \in \mathrm{S}-\mathrm{GLC}(\mathrm{X}), \mathrm{W} \in \mathrm{Z}$. Therefore, hog is S-GLcontinuous.

4.10 Theorem If $\mathrm{g}: \mathrm{X} \rightarrow \mathrm{Y}$ is $\mathrm{S}-\mathrm{GL}$ - irresolute and $\mathrm{h}: \mathrm{Y} \rightarrow \mathrm{Z}$ is S-GL-continuous, then $\mathrm{h}$ o $\mathrm{g}: \mathrm{X} \rightarrow \mathrm{Z}$ is $\mathrm{S}-\mathrm{GL}$ - continuous.

Proof Let $\mathrm{g}: \mathrm{X} \rightarrow \mathrm{Y}$ is $\mathrm{S}-\mathrm{GL}$ - irresolute and $\mathrm{h}: \mathrm{Y} \rightarrow$ $\mathrm{Z}$ is S-GL-continuous. By the definitions, $\mathrm{g}^{-1}(\mathrm{~V}) \in \mathrm{S}$-GLC $(\mathrm{X})$, for $\mathrm{V} \in \mathrm{S}-\mathrm{GLC}(\mathrm{Y})$ and $\mathrm{h}^{-1}(\mathrm{~W}) \in \mathrm{S}-\mathrm{GLC}(\mathrm{Y})$, for $\mathrm{W} \in \mathrm{Z}$. Let $\mathrm{W} \in \mathrm{Z}$. Then $(h \circ g)^{-1}(\mathrm{~W})=\left(\mathrm{g}^{-1} \mathrm{~h}^{-1}\right)(\mathrm{W})=\mathrm{g}^{-1}(\mathrm{~h}$ $\left.{ }^{1}(\mathrm{~W})\right)=\mathrm{g}^{-1}(\mathrm{~V})$, for $\mathrm{V} \in \mathrm{S}-\mathrm{GLC}(\mathrm{Y})$. This implies, (hog) ${ }^{1}(\mathrm{~W})=\mathrm{g}^{-1}(\mathrm{~V}) \in \mathrm{S}-\mathrm{GLC}(\mathrm{X}), \mathrm{W} \in \mathrm{Z}$. Hence hog is $\mathrm{S}$ GL- continuous.
4.11 Theorem If $\mathrm{g}: \mathrm{X} \rightarrow \mathrm{Y}$ and $\mathrm{h}: \mathrm{Y} \rightarrow \mathrm{Z}$ are $\mathrm{S}-\mathrm{GL}$ - irresolute, then $\mathrm{h}$ o $\mathrm{g}: \mathrm{X} \rightarrow \mathrm{Z}$ is also S-GL irresolute.

Proof By the hypothesis and the definitions, we have $\mathrm{g}$ ${ }^{1}(\mathrm{~V}) \in \mathrm{S}-\mathrm{GLC}(\mathrm{X})$, for $\mathrm{V} \in \mathrm{S}-\mathrm{GLC}(\mathrm{Y})$ and $\mathrm{h}^{-1}(\mathrm{~W}) \in \mathrm{S}$ GLC (Y), for $\mathrm{W} \in \mathrm{S}-\mathrm{GLC}(\mathrm{Z})$. Let $\mathrm{W} \in \mathrm{S}-\mathrm{GLC}(\mathrm{Z})$. Then $(h \circ g)^{-1}(W)=\left(g^{-1} h^{-1}\right)(W)=g^{-1}\left(h^{-1}(W)\right)=g^{-1}(V)$, for $V \in$ S-GLC (Y). Therefore, $(\text { hog })^{-1}(\mathrm{~W})=\mathrm{g}^{-1}(\mathrm{~V}) \in \mathrm{S}-\mathrm{GLC}(\mathrm{X})$, $\mathrm{W} \in \mathrm{S}-\mathrm{GLC}(\mathrm{Z})$. Thus hog is S-GL - irresolute.

\section{REFERENCES}

[1] Balachandran, K., Sundaram, P. and Maki, H. 1996 Generalized locally closed sets and GLC-continuous functions, Indian J. Pure Appl. Math., 27(3) (1996), 235-244.

[2] Bourbaki, N. 1966 General Topology, Part 1, AddisonWesley (Reading, Mass, 1966).

[3] Devi, R., Sampathkumar, S. and caldas, 2008 M. On supra S-open sets and S-continuous functions, General Mathematics, 16(2) (2008), 77-84.

[4] Ganster, M. and Reilly, I.L. 1990 A decomposition of continuity, Acta Math Hungarica, 56 (3-4) (1990), 299-301.

[5] Ganster, M. and Reilly, I.L. 1989 Locally closed sets and LC Continuous functions, International J.Math. and Math.Sci ., 12 (1989), 417-424.

[6] Jin Han Park and Jin Keun Park. 2000 On Semi Generalized Locally closed sets and SGLCcontinuous functions, I.pure appl. Math, 31(9) ( Sep 2000) 1103- 1112.

[7] Kamaraj, M., Ramkumar, G. and Ravi, O. 2012 On Supra quotient mappings, International Journal of Mathematical Archive, 3 (1) (2012), 245-252.

[8] Kuratawski, C. and Sierpinski, W. 1921 Sur les Differences de deux ensembles fermes, Tohoku Math.J.20 (1921),22-25.

[9] Mashhour, A.S., Allam, A.A., Mahmond, F.S. and Khedr, F.H. 1983 On Supratooplogical spaces, Indian J.Pure and Appl. Math., 14(4) (1983), 502-610.

[10] Ravi, O., Ramkumar, G., and Kamaraj, M. 2011 On Supra g-closed sets, International Journal of Advances in Pure and Applied Mathematics, 1(2) (2011), 52-66.

[11] Stone, A.H. 1980 Absolutely FG spaces, Proc. Amer. Math Soc. 80 (1980), 515-520.

[12] Sayed, O.R. and Noiri, T. 2010 On supra b-open sets and supra b-continuity on topological spaces, European J.Pure and Appl. Math., 3(2) (2010), 295 302. 